\title{
Preparation of Poly-( $p$-aminobenzoic acid)/Multiwall Carbon Nanotubes Composite Film Modified Glassy Carbon Electrode and Application to Detect Catechol and Hydroquinone Simultaneously \\ Jianying QU,* Tongfang LOU, Shiping KANG, and Xueping DU
}

\author{
Institute of Environmental and Analytical Sciences, College of Chemistry and Chemical Engineering, \\ Henan University, Kaifeng, Henan 475004, P. R. China
}

* Corresponding author: QJY405407@163.com, lilyqujy@yahoo.com.cn

\begin{abstract}
The electrochemical reaction of catechol (CC) and hydroquinone (HQ) was investigated at poly- $(p$-aminobenzoic acid) ( $p$-ABA)/multiwall carbon nanotubes (MWCNTs) composite film modified glassy carbon (GC) electrode via cyclic voltammetry (CV). Separation of the peak potentials for CC and $\mathrm{HQ}$ was about $105 \mathrm{mV}$ in $0.1 \mathrm{~mol} / \mathrm{L} \mathrm{H} \mathrm{SO}_{4}$, which makes it suitable for simultaneous determination of these compounds. Under optimized conditions, the oxidation current of $\mathrm{CC}$ and $\mathrm{HQ}$ have been enhanced linearly with the concentration in the range of $1 \times 10^{-5}$ $1 \times 10^{-3} \mathrm{~mol} / \mathrm{L}(r=0.9979)$ and $1 \times 10^{-5}-1 \times 10^{-3} \mathrm{~mol} / \mathrm{L}(r=0.9948)$, with the detection limit of CC and HQ $4 \times 10^{-6}$ and $2.7 \times 10^{-6} \mathrm{~mol} / \mathrm{L}$, respectively. The proposed method has been applied to determine CC and $\mathrm{HQ}$ simultaneously with good results, which shows excellent stability and reproducibility.
\end{abstract}

(c) The Electrochemical Society of Japan, All rights reserved.

Keywords : Poly-( $p$-aminobenzoic acid), Multiwall Carbon Nanotubes, Catechol, Hydroquinone

\section{Introduction}

Phenolics are widely used chemical materials, and also a class of organic pollutants that are harmful to both humans and environment. Therefore, it is of great significance to study a fast, easy, accurate detection method. Catechol (CC) and hydroquinone (HQ) are each other's isomers, their physical and chemical properties are very similar, so they are difficult to separate and analyze quantitatively by chemical or physical methods. At present, the determination of dihydroxybenzene isomers have been performed with spectrophotometry, ${ }^{1,2}$ high performance liquid chromatography, ${ }^{3}$ fluorescence spectrometry ${ }^{4}$ and capillary electrophoresis ${ }^{5}$ and so on. However, these methods usually require pretreatment of samples, complicated operation, a large quantities of reagent, and are not suitable for field test.

CC and HQ have electrochemical activity, easily oxidized, so they are available for electrochemical detection methods. ${ }^{6,7}$ However, there is a great number of challenges for the simultaneous determination of $\mathrm{CC}$ and $\mathrm{HQ}$. One major difficulty is that voltammetric peaks corresponding to the oxidation peaks of the two phenol isomers are seriously overlapped on most conventional solid electrode. ${ }^{8,9}$ In addition, their competitive adsorption at the electrode surface makes the relationship between the voltammetric response and concentration in the mixtures nonlinear. ${ }^{10}$ In order to solve these problems, many chemical modified electrodes were prepared for the simple, non-separate and simultaneous determination of isomers, such as carbon nanotubes modified electrode ${ }^{11}$ and poly (glutamic acid) modified electrode. ${ }^{12}$

Polymer-modified electrodes (PMEs) have received attention in recent years, ${ }^{13,14}$ due to their good stability, reproducibility and homogeneity in electrochemical deposition and strong adherence to electrode surface. Electro-polymerization is a nice approach to immobilize polymers on electrodes by adjusting the electrochemical parameters to control the film thickness, permeation and charge transport characteristics.

In this article, we prepared firstly the poly-( $p$-aminobenzoic acid)/MWCNTs composite film via electrochemically polymeriza- tion of $p$-aminobenzoic acid on the MWCNTs/GC modified electrode to explore the electrochemical behavior of $\mathrm{CC}$ and HQ. This kind of modified electrode can effectively catalyze the redox of $\mathrm{CC}$ and $\mathrm{HQ}$ in the $0.10 \mathrm{~mol} / \mathrm{L} \mathrm{H}_{2} \mathrm{SO}_{4}$, which provide a new method to detect $\mathrm{CC}$ and HQ simultaneously with satisfactory results.

\section{Experimental}

\subsection{Apparatus and reagents}

Electrochemical experiments were performed with a CHI650 electrochemical workstation (USA, CHI). A conventional threeelectrode system was used where glassy carbon (GC) electrode ( $3 \mathrm{~mm}$ diameter) or chemically modified GC electrodes, rotating platinum wire electrode and $\mathrm{ag} / \mathrm{AgCl}$ (saturated $\mathrm{KCl}$ ) were used as working, counter and reference electrodes, respectively. All potentials in this work referred to this reference electrode.

Multi-walled carbon nanotubes (MWCNTs) (Diameter 10-15 nm, University of Marburg, Germany, Department of Chemistry, Materials Science Center), $p$-aminobenzoic acid ( $p$-ABA) (fluka), N,N-dimethylformamide (DMF) (Kermel, Tianjin Chemical Reagent Co., Ltd.), Other reagents were of analytical grade and the water were redistilled water.

\subsection{Preparation of $p-p-A B A / M W C N T s$ modified electrode}

GC electrode was polished with $1.0,0.3$, and $0.05 \mu \mathrm{m}$ alumina slurry sequentially and then washed ultra-sonically in water and ethanol for a few minutes, respectively, and dried for use.

For the preparation of MWCNTs/GC, $3 \mu \mathrm{L}$ of the MWCNTs suspension $(1 \mathrm{mg} / \mathrm{mL})$, which was prepared by dispersing the desired amount of purified MWCNTs in DMF with the aid of ultrasonic oscillation, was dropped on GC surface, followed by evaporating the solvent under an infrared lamp. Then the prepared MWCNTs/GC electrode was immersed in a $0.10 \mathrm{~mol} / \mathrm{L}$ PBS containing $2 \times 10^{-3} \mathrm{~mol} / \mathrm{L} p$-ABA solution ( $\mathrm{pH} \mathrm{7.0)}$ and was polymerized by cyclic scanning between -1.5 to $+2.5 \mathrm{~V}$ at $100 \mathrm{mV} / \mathrm{s}$ for 10 cycles to obtain the p- $p$-ABA/MWCNTs/GC electrode. 


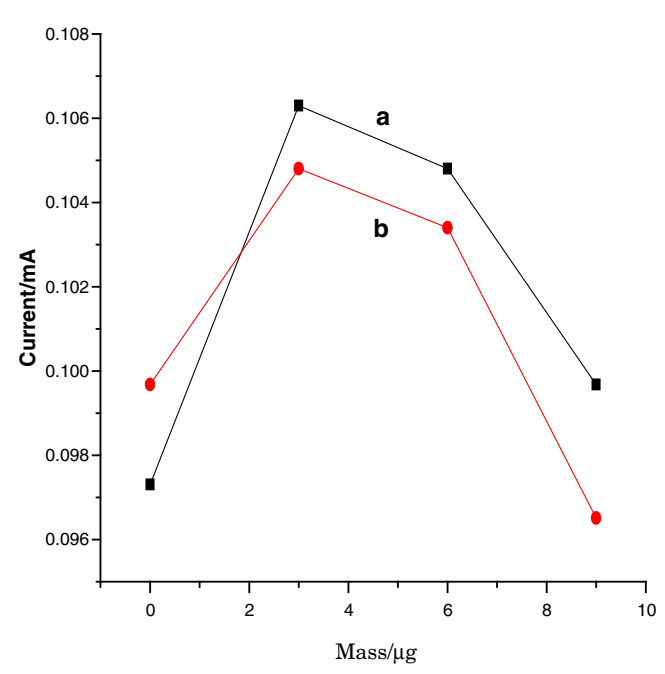

Figure 1. (Color online) Effect of MWCNTs content for catalytic current $\mathrm{CC}$ (a) and $\mathrm{HQ}$ (b) in $0.1 \mathrm{~mol} / \mathrm{L} \mathrm{H}_{2} \mathrm{SO}_{4}$ containing the mixture of $1 \mathrm{mmol} / \mathrm{L} \mathrm{CC}$ and $\mathrm{HQ}$, scan rate: $50 \mathrm{mV} / \mathrm{s}$.

Before electrochemical measurement, the modified electrode was activated by cyclic voltammetry from -1.0 to $+1.0 \mathrm{~V}$ in $0.10 \mathrm{~mol} / \mathrm{L}$ PBS (pH 7.0).

\section{Results and Discussion}

\subsection{Optimization of experimental conditions \\ 3.1.1 Optimization of MWCNTs content}

The same concentration $(1 \mathrm{mg} / \mathrm{mL})$ of MWCNTs with different volume of $3,6,9 \mu \mathrm{L}$ was modified on the bare GC electrode. Then the same procedures were performed for electrochemical polymerization of $p$-ABA on the MWCNTs/GC modified electrode. The catalysis of CC and HQ were studied by the p- $p$-ABA/MWCNTs/ GC modified electrode. Figure 1 shows that the catalytic current increased with the increase of MWCNTs but reduced when the content of MWCNTs is more than $3 \mu \mathrm{L}$. That means the film becomes certain thicker, which hinders the electron transfer and is not conducive enough to react with the substrate. So, $3 \mu \mathrm{L}$ MWCNTs was chosen as the optimum content.

3.1.2 Optimization of electrochemical polymerization cycles

Cyclic voltammetry was used to form the polymer film. The prepared MWCNTs/GC electrode was electrochemically polymerized with different cycles. Figure 2 showed that the catalytic current increased with the increase of polymerization cycles. But when the polymerization scans was more than 10 cycles, the current almost does not increase. So, 10 cycles of electrochemical polymerization was regard as the optimum condition.

3.1.3 Choice of base solution

Four kinds of solution were chosen as base solution, which are $0.1 \mathrm{~mol} / \mathrm{L} \quad \mathrm{K}_{2} \mathrm{HPO}_{4}-\mathrm{KH}_{2} \mathrm{PO}_{4}, 0.1 \mathrm{~mol} / \mathrm{L} \quad \mathrm{HAc}-\mathrm{NaAc}, 0.1 \mathrm{~mol} / \mathrm{L}$ $\mathrm{H}_{2} \mathrm{SO}_{4}$, and $0.1 \mathrm{~mol} / \mathrm{L} \mathrm{HCl}$. As shown in Table 1, the peak current of the mixed solution of hydroquinone is maximal and the reversibility is the best in $\mathrm{H}_{2} \mathrm{SO}_{4}$. So we choose the $0.1 \mathrm{~mol} / \mathrm{L} \mathrm{H}_{2} \mathrm{SO}_{4}$ as the optimum base solution.

\subsection{Electrochemical performance of the sensor}

The electro-catalytic activity of the $\mathrm{p}-\mathrm{p}$-ABA/MWCNTs composite film modified GC was demonstrated by the comparison of the $\mathrm{CVs}$ of $1 \mathrm{mmol} / \mathrm{L}$ the mixed solution of hydroquinone in $0.1 \mathrm{~mol} / \mathrm{L}$ $\mathrm{H}_{2} \mathrm{SO}_{4}$, experimental results were recorded in Fig. 3 for four different working electrodes. It is clearly that there was only a broad redox peak of curve a, indicating that the redox peaks of CC and HQ overlapped at bare GC. Except for the bare GC electrode, two pairs

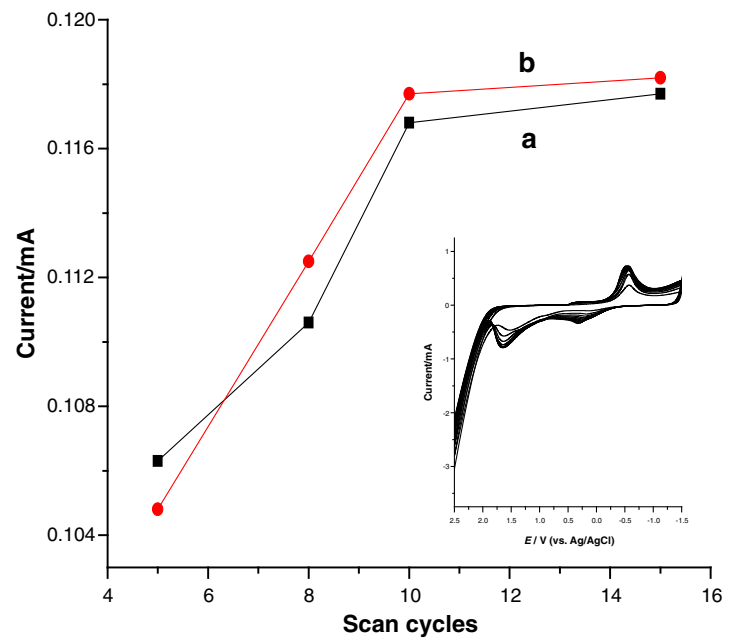

Figure 2. (Color online) Effect of electrochemical polymerization scans for $\mathrm{CC}$ (a) and $\mathrm{HQ}$ (b) in $0.1 \mathrm{~mol} / \mathrm{L} \mathrm{H}_{2} \mathrm{SO}_{4}$ containing the mixture of $1 \mathrm{mmol} / \mathrm{L} \mathrm{CC}$ and $\mathrm{HQ}$, the inserted chart is the electrochemical polymerization of $p$-ABA figure, scan rate: $50 \mathrm{mV} / \mathrm{s}$.

Table 1. Peak current and peak potential of CC (A) and HQ (B) in different base solution.

\begin{tabular}{|c|c|c|c|c|c|}
\hline $\mathbf{A}$ & $\begin{array}{c}\text { Epa } \\
(\mathrm{mV})\end{array}$ & $\begin{array}{l}\text { Ipa } \\
(\mu \mathrm{A})\end{array}$ & $\begin{array}{l}\text { Epc } \\
(\mathrm{mV})\end{array}$ & $\begin{array}{c}\text { Ipc } \\
(\mu \mathrm{A})\end{array}$ & $\begin{array}{c}\Delta \mathrm{Ep} \\
(\mathrm{mV})\end{array}$ \\
\hline $\mathrm{H}_{2} \mathrm{SO}_{4}$ & 573.9 & 175.7 & 537.2 & 88.8 & 36.7 \\
\hline $\mathrm{HCl}$ & 555.6 & 168.8 & 516.4 & 75.0 & 39.2 \\
\hline HAc-NaAc & 430.0 & 123.6 & 300.7 & 68.1 & 129.3 \\
\hline $\mathrm{K}_{2} \mathrm{HPO}_{4}-\mathrm{KH}_{2} \mathrm{PO}_{4}$ & 397.3 & 113.9 & 291.5 & 62.1 & 105.8 \\
\hline B & $\begin{array}{c}\text { Epa } \\
(\mathrm{mV})\end{array}$ & $\begin{array}{c}\text { Ipa } \\
(\mu \mathrm{A})\end{array}$ & $\begin{array}{c}\text { Epc } \\
(\mathrm{mV})\end{array}$ & $\begin{array}{c}\text { Ipc } \\
(\mu \mathrm{A})\end{array}$ & $\begin{array}{c}\Delta \mathrm{Ep} \\
(\mathrm{mV})\end{array}$ \\
\hline $\mathrm{H}_{2} \mathrm{SO}_{4}$ & 470.5 & 164.9 & 432.7 & 125.7 & 37.8 \\
\hline $\mathrm{HCl}$ & 453.6 & 170.6 & 414.4 & 118.5 & 39.2 \\
\hline HAc-NaAc & 325.5 & 115.8 & 172.5 & 105.8 & 153.0 \\
\hline $\mathrm{K}_{2} \mathrm{HPO}_{4}-\mathrm{KH}_{2} \mathrm{PO}_{4}$ & 281.1 & 117.2 & 155.6 & 105.0 & 125.5 \\
\hline
\end{tabular}

of peaks are exhibited, which indicate that the oxidation and reduction peaks of $\mathrm{CC}$ and $\mathrm{HQ}$ can be separated at other three modified electrodes. And, at the MWCNTs/GC electrode (curve b), two pairs of peaks are exhibited, which indicate that the oxidation and reduction peaks of $\mathrm{CC}$ and $\mathrm{HQ}$ can be separated, but the peaks current are rather small. Although both the oxidation and the reduction peaks of $\mathrm{CC}$ and $\mathrm{HQ}$ separate well at $\mathrm{p}-p-\mathrm{ABA} / \mathrm{GC}$ electrode (curve c), their peak currents are still smaller than those at p-p-ABA/MWCNTs/GC (curve d).

Obviously, it can be observed that the peak current at p- $p$-ABA/ MWCNTs/GC electrode is nearly two times higher than the response currents at MWCNTs/GC electrode and increased by $10 \%$ for the $\mathrm{p}-p-\mathrm{ABA} / \mathrm{GC}$ electrode. The reversibility of $\mathrm{CC}$ and HQ were significantly improved together with the current signal increasing. For $\mathrm{CC}$, the oxidation peak potential negatively shifts to $574 \mathrm{mV}$ and the reduction peak positively shifts to $537 \mathrm{mV}$ with $\Delta \mathrm{Ep}=37 \mathrm{mV}$; For $\mathrm{HQ}$, the oxidation peak potential negatively shifts to $471 \mathrm{mV}$ and the reduction peak positively shifts to $433 \mathrm{mV}$ with $\Delta \mathrm{Ep}=38 \mathrm{mV}$. The peak-to-peak potential separation between $\mathrm{CC}$ and HQ was $105 \mathrm{mV}$. 


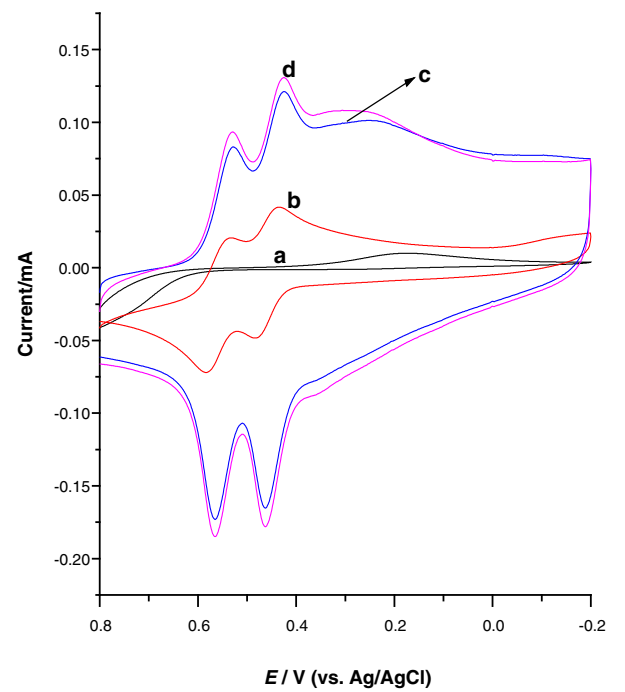

Figure 3. (Color online) Cyclic voltammograms of the mixture of $1 \mathrm{mmol} / \mathrm{L} \mathrm{CC}$ and $\mathrm{HQ}$ in the $0.1 \mathrm{~mol} / \mathrm{L} \mathrm{H}_{2} \mathrm{SO}_{4}$ at different electrodes, (a) GC, (b) MWCNTs/GC, (c) p-p-ABA/GC, and (d) p-p-ABA/MWCNTs/GC, scan rate: $50 \mathrm{mV} / \mathrm{s}$.

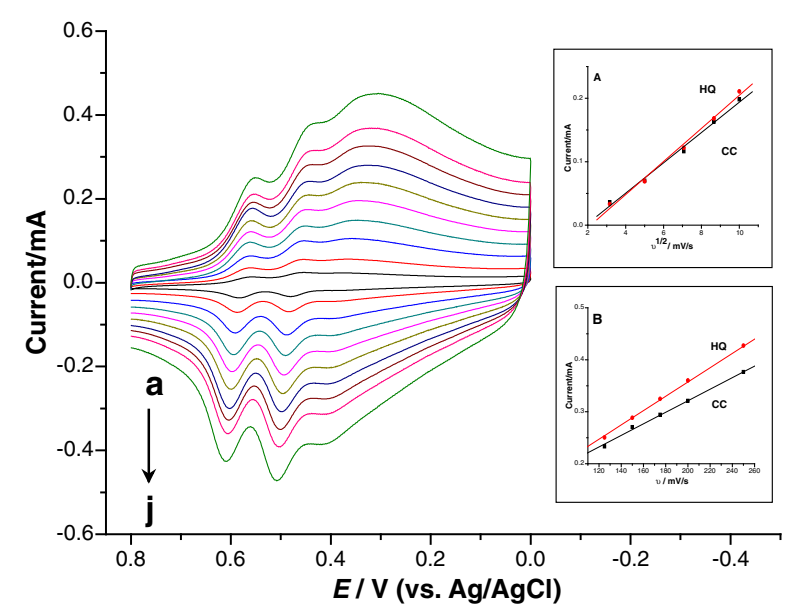

Figure 4. (Color online) Cyclic voltammograms of $\mathrm{p}-p-\mathrm{ABA} /$ MWCNTs/GC electrode at different scan rates $(\mathrm{mV} / \mathrm{s})$ of $\mathrm{CC}$ and HQ in the range at a-j: 10, 25, 50, 75, 100, 125, 150, 175, 200, 250.

The improvement of peak current together with sharpness of the peak clearly demonstrated that the $\mathrm{p}-p$-ABA/MWCNTs composite film acts as an efficient promoter to enhance the electrochemical process, which is probably caused by the synergistic effect of the electro-catalytic property of $\mathrm{p}-p$-ABA and MWCNTs. These results indicate that the $\mathrm{p}-p$-ABA/MWCNTs composite film modified electrode can not only identify the CC and HQ simultaneously, but also improve the detection sensitivity.

\subsection{Influence of scan rate}

The scan rate dependence of peak current for the $\mathrm{p}-p-\mathrm{ABA} /$ MWCNTs/GC electrode is presented in Fig. 4. It is clear that the anodic peak grew continuously with scan rate increasing. There is a good linear relationship between peak current and the square root of the scan rate $\left(v^{1 / 2}\right)$ from 10 to $100 \mathrm{mV} / \mathrm{s}$. The regression equations were $i_{p}=-0.45158+0.23896 v^{1 / 2}(r=0.9963)$ for $\mathrm{CC}$ and $i_{p}=$ $-0.5608+0.26075 v^{1 / 2}(r=0.9963)$ for $\mathrm{HQ}$, demonstrating the diffusion controlled process of $\mathrm{CC}$ and $\mathrm{HQ}$ at the p-p-ABA/ MWCNTs/GC electrode at lower scan rates. However, there is a good linear relationship between peak current and the scan rate $(v)$

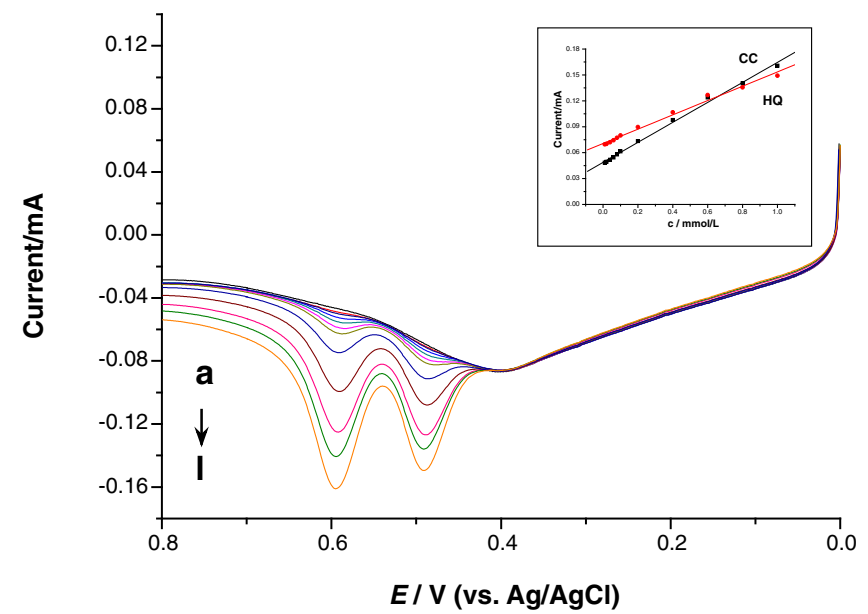

Figure 5. (Color online) $\mathrm{CV}$ of various concentrations of $\mathrm{CC}$ and HQ both from $1.0 \times 10^{-5}$ to $1.0 \times 10^{-3} \mathrm{~mol} / \mathrm{L}$ in $0.1 \mathrm{~mol} / \mathrm{L} \mathrm{H}_{2} \mathrm{SO}_{4}$ : (a) $0 \mathrm{~mol} / \mathrm{L}$, (b) $1.0 \times 10^{-5} \mathrm{~mol} / \mathrm{L}$, (c) $2.0 \times 10^{-5} \mathrm{~mol} / \mathrm{L}$, (d) $4.0 \times$ $10^{-5} \mathrm{~mol} / \mathrm{L}$, (e) $6.0 \times 10^{-5} \mathrm{~mol} / \mathrm{L}$, (f) $8.0 \times 10^{-5} \mathrm{~mol} / \mathrm{L}$, (g) $1.0 \times$ $10^{-4} \mathrm{~mol} / \mathrm{L}$, (h) $2.0 \times 10^{-4} \mathrm{~mol} / \mathrm{L}$, (i) $4.0 \times 10^{-4} \mathrm{~mol} / \mathrm{L}$, (j) $6.0 \times$ $10^{-4} \mathrm{~mol} / \mathrm{L}$, (k) $8.0 \times 10^{-4} \mathrm{~mol} / \mathrm{L}$, (l) $1.0 \times 10^{-3} \mathrm{~mol} / \mathrm{L}$, scan rate: $50 \mathrm{mV} / \mathrm{s}$.

from 125 to $250 \mathrm{mV} / \mathrm{s}$. The regression equations were $\mathrm{i}_{\mathrm{p}}=$ $0.99079+0.0111 v \quad(\mathrm{r}=0.9991)$ for $\mathrm{CC}$ and $\mathrm{i}_{\mathrm{p}}=0.82118+$ $0.01375 \mathrm{v}(\mathrm{r}=0.9996)$ for HQ, which strongly suggested that the redox reactions of $\mathrm{CC}$ and $\mathrm{HQ}$ were surface adsorption controlled at higher scan rates.

\subsection{Simultaneous determination of $\mathrm{CC}$ and $\mathrm{HQ}$}

The utilization of the $\mathrm{p}-\mathrm{p}$-ABA/MWCNTs/GC for the simultaneous determination of $\mathrm{CC}$ and $\mathrm{HQ}$ was demonstrated by changing their concentration. As shown in Fig. 5, a linear ranges for concentration of CC and HQ were $1.0 \times 10^{-5}-1.0 \times 10^{-3} \mathrm{~mol} / \mathrm{L}$ and $1.0 \times 10^{-5}-1.0 \times 10^{-3} \mathrm{~mol} / \mathrm{L}$ with the linear equations of $\mathrm{i}_{\mathrm{P}}=$ $4.87502+11.5799 \mathrm{c} \quad(\mathrm{r}=0.9979)$ and $\mathrm{i}_{\mathrm{p}}=7.06337+8.28607 \mathrm{c}$ $(\mathrm{r}=0.9948)$, respectively. The relative standard deviations of CC and HQ were 2.11 and $0.26 \%(\mathrm{n}=6, \mathrm{c}=0.6 \mathrm{mmol} / \mathrm{L})$, respectively. When the signal to noise ratio is 3 , the detection limits of CC and HQ were $4.0 \times 10^{-6}$ and $2.7 \times 10^{-6} \mathrm{~mol} / \mathrm{L}$ respectively.

The p-p-ABA/MWCNTs/GC modified electrode was studied by continuous cyclic voltammetry for 50 cycles in $0.6 \mathrm{mmol} / \mathrm{L}$ mixed solution of hydroquinone. The peak current is almost unchanged. And, the redox peak currents of CC and HQ did not change after keeping the electrode in air for a month. This demonstrated that the modified electrode has a good stability.

For oxidation peak current, in the mixed sample containing $0.6 \mathrm{mmol} / \mathrm{L} \mathrm{CC}$ and $\mathrm{HQ}$, the relative standard deviations (RSD) of 6 successive parallel determinations were $2.11 \%$ for $\mathrm{CC}$ and $0.26 \%$ for HQ, respectively. This showed that the electrode has good reproducibility. The excellent stability and reproducibility of the composite modified electrode make them attractive for the fabrication of electrochemical sensors.

\subsection{Analytical application}

Under the optimal conditions, the p-p-ABA/MWCNTs/GC modified electrode was used for the detection of $\mathrm{CC}$ and $\mathrm{HQ}$ in $0.1 \mathrm{~mol} / \mathrm{L} \mathrm{H}_{2} \mathrm{SO}_{4}$. According to the blank standard addition method, we added different concentrations of the mixed solution of hydroquinone to the electrolytic cell, then determined their contents and calculated their recoveries. As shown in Table 2, the recovery of CC and HQ were $98.8-108.2 \%$ and $98.0-114.5 \%$, and the average recovery of $\mathrm{CC}$ and $\mathrm{HQ}$ were 104.8 and $108.2 \%$, respectively. It 
Table 2. Recovery of the $\mathrm{p}-p$-ABA/MWCNT/GC modified electrode (A) recovery of $\mathrm{CC},(\mathrm{B})$ recovery of $\mathrm{HQ}$.

A

\begin{tabular}{cccc}
\hline $\begin{array}{c}\text { Added/ } \\
\left(10^{-4} \mathrm{~mol} / \mathrm{L}\right)\end{array}$ & $\begin{array}{c}\text { Measured value/ } \\
\left(10^{-4} \mathrm{~mol} / \mathrm{L}\right)\end{array}$ & $\begin{array}{c}\text { Recovery } \\
(\%)\end{array}$ & $\begin{array}{c}\text { Average } \\
\text { recovery }(\%)\end{array}$ \\
\cline { 1 - 3 } 2.00 & 2.13 & 106.5 & \\
\cline { 1 - 3 } & 4.23 & 105.8 & \multirow{2}{*}{104.8} \\
\cline { 1 - 3 } 6.00 & 6.49 & 108.2 & \\
\cline { 1 - 3 } 8.00 & 7.9 & 98.8 & \\
\hline
\end{tabular}

B

\begin{tabular}{cccc}
\hline $\begin{array}{c}\text { Added/ } \\
\left(10^{-4} \mathrm{~mol} / \mathrm{L}\right)\end{array}$ & $\begin{array}{c}\text { Measured value/ } \\
\left(10^{-4} \mathrm{~mol} / \mathrm{L}\right)\end{array}$ & $\begin{array}{c}\text { Recovery } \\
(\%)\end{array}$ & $\begin{array}{c}\text { Average } \\
\text { recovery }(\%)\end{array}$ \\
\cline { 1 - 3 } 2.00 & 2.29 & 114.5 & \\
\cline { 1 - 3 } & 4.35 & 108.8 & \multirow{2}{*}{108.2} \\
\cline { 1 - 3 } 6.00 & 6.69 & 111.5 & \\
\hline 8.00 & 7.84 & 98.0 & \\
\hline
\end{tabular}

shows that the proposed method can be efficiently used for the determination of CC and HQ simultaneously.

A comparison of the proposed method with the recent reports was listed in Table 3, which indicated that the proposed electrode is superior to the existing electrodes because of its reversibility, stability, reproducibility and ability to effectively determine CC and HQ simultaneously.

\section{Conclusion}

The present study demonstrates an excellent approach for the simultaneous determination of $\mathrm{CC}$ and $\mathrm{HQ}$ based on $\mathrm{p}-\mathrm{p}$-ABA/ MWCNTs composite film modified GC electrode. The improvement of peak current together with sharpness of the peak shape clearly demonstrated that the $\mathrm{p}-\mathrm{p}-\mathrm{ABA} / \mathrm{MWCNTs} / \mathrm{GC}$ composite film acts as an efficient promoter to enhance the electrochemical process, which is probably caused by the synergistic effect of the electrocatalytic property of $\mathrm{p}-p$-ABA and MWCNTs. The excellent continuous stability and reproducibility of the composite modified electrode make them attractive for the fabrication of electrochemical sensors and potential applications.

\section{References}

1. E. C. Figueiredo, C. R. T. Tarley, L. T. Kubota, S. Rath, and M. A. Z. Arruda, Microchem. J., 85, 290 (2007).

2. H. F. Li, C. G. Xie, J. J. Zong, and H. K. Zhou, Metall. Anal., 29, 31 (2009).

3. S. L. Fan, L. K. Zhang, and J. M. Lin, Talanta, 68, 646 (2006).

4. Y. L. Xue, S. X. Ren, and L. Gao, J. Instrum. Anal., 29, 1147 (2010).

5. T. Y. Xie, Q. W. Liu, Y. R. Shi, and Q. Y. Liu, J. Chromatogr. A, 1109, 317 (2006).

6. M. Diaconu, S. C. Litescu, and G. L. Radu, Mikrochim. Acta, 172, 177 (2011).

7. K. J. Huang, S. Yu, L. Wang, T. Gan, and M. Li, Acta Chim. Sin., 70, 735 (2012).

8. C. Zhao, J. F. Song, and J. C. Zhang, Anal. Bioanal. Chem., 374, 498 (2002).

9. A. Gutés, F. Céspedes, S. Alegret, and M. Valle, Biosens. Bioelectron., 20, 1668 (2005).

10. R. M. Carvalho, C. Mello, and L. T. Kubota, Anal. Chim. Acta, 420, 109 (2000).

11. S. M. Yang, Z. P. Wei, G. H. Hu, D. Jiang, A. H. Huang, and L. Z. Zheng, Chem. J. Chin. Univ., 31, 264 (2010).

12. C. Y. Wang, T. Y. You, and J. Tian, Chin. J. Anal. Chem., 39, 528 (2011).

13. X. Y. Ma, Chem. Res. Appl., 20, 980 (2008).

14. D. P. Santos, M. V. B. Zanoni, M. F. Bergamini, A.-M. Chiorcea-Paquim, V. C. Diculescu, and A. M. O. Brett, Electrochim. Acta, 53, 3991 (2008).

15. P. Yang, Q. Y. Zhu, Y. H. Chen, and F. W. Wang, J. Appl. Polym. Sci., 113, 2881 (2009).

16. L. Wang, P. F. Huang, H. J. Wang, J. Y. Bai, L. Y. Zhang, and Y. Q. Zhao, Int. J. Electrochem. Sci., 2, 216 (2007).

17. S. M. Wang, W. Y. Su, and S. H. Cheng, Int. J. Electrochem. Sci., 5, 1649 (2010).

18. A. J. S. Ahammad, S. Sarker, M. A. Rahman, and J. J. Lee, Electroanalysis, 22, 694 (2010).

19. A. J. S. Ahammad, Md. M. Rahman, G. R. Xu, S. Kim, and J. J. Lee, Electrochim. Acta, 56, 5266 (2011).

20. L. T. Wang, Y. Zhang, Y. L. Du, D. B. Lu, Y. Z. Zhang, and C. M. Wang, J. Solid State Electrochem., 16, 1323 (2012).

21. K. Q. Deng, C. X. Li, X. F. Li, and G. R. Xu, Anal. Lett., 45, 883 (2012).

22. D. M. Zhao, X. H. Zhang, L. J. Feng, L. Jia, and S. F. Wang, Colloids Surf., B, 74, 317 (2009).

23. H. S. Yin, Q. M. Zhang, Y. L. Zhou, and Q. Ma, Electrochim. Acta, 56, 2748 (2011).

Table 3. The reversibility, reproducibility, and stability of the proposed electrode and the reported methods.

\begin{tabular}{|c|c|c|c|c|c|c|c|}
\hline \multirow{2}{*}{ Reference } & \multicolumn{2}{|c|}{$\Delta \mathrm{Ep}(\mathrm{mV})$} & \multirow{2}{*}{$\begin{array}{c}\Delta \text { Ep between } \\
\mathrm{CC} \text { and HQ }(\mathrm{mV})\end{array}$} & \multicolumn{2}{|c|}{ RSD (\%) } & \multirow{2}{*}{ Stability } & \multirow{2}{*}{ Method } \\
\hline & $\mathrm{CC}$ & HQ & & $\mathrm{CC}$ & HQ & & \\
\hline 15 & 33 & 32 & 104 & - & - & a month & DPV \\
\hline 16 & 44 & 55 & 103 & - & - & a week & DPV \\
\hline 17 & 84 & 80 & - & 1.47 & 1.82 & - & SWV \\
\hline 18 & 47 & 49 & - & 0.73 & 0.61 & $\begin{array}{l}i_{p} \text { reduced } 5 \% \\
\text { after } 20 \text { cycles }\end{array}$ & DPV \\
\hline 19 & 56 & 63 & - & 0.31 & 0.37 & $\begin{array}{l}i_{p} \text { reduced } 2 \% \\
\text { after } 40 \text { cycles }\end{array}$ & DPV \\
\hline 20 & 31 & 33 & 108 & - & - & - & DPV \\
\hline 21 & 60 & 55 & 105 & 2.8 & 2.2 & a month & DPV \\
\hline 22 & - & - & - & 1.71 & 1.52 & 3 week & DPV \\
\hline 23 & - & - & 96 & - & - & 15 days & DPV \\
\hline This work & 37 & 38 & 105 & 2.11 & 0.26 & $\begin{array}{l}\mathrm{i}_{\mathrm{p}} \text { unchanged after } 50 \\
\text { cycles or a month later }\end{array}$ & $\mathrm{CV}$ \\
\hline
\end{tabular}

